\title{
A METHOD FOR DETERMINING 1, 4-BENZOTHIAZINE DERIVATIVES IN RAT PLASMA BY HPLC AND ITS APPLICATION TO A PHARMACOKINETIC STUDY
}

\author{
AMIT RAI ${ }^{\text {, }}$ VINIT RAJ ${ }^{a}$, ASHOK K. SINGHa, AMIT K. KESHARIa, SUDIPTA SAHA ${ }^{a^{*}}$ \\ aDepartment of Pharmaceutical Sciences, Babasaheb Bhimrao Ambedkar University, Vidya Vihar, Rae Bareli Road, Lucknow 226025, \\ India \\ Email: sudiptapharm@gmail.com
}

Received: 29 Jan 2017 Revised and Accepted: 02 Nov 2017

\section{ABSTRACT}

Objective: The objective of the study was to develop, optimize and validate of a new reverse-phase high-performance liquid chromatography (RPHPLC) method for the determining 1,4-benzothiazine derivatives (AR13 and AR15) in a biological sample of rat plasma. The 1,4-benzothiazine derivatives are produced by the synthetic reactions.

Methods: RP-HPLC separation was performed using an ODS-2 Hypersil column with gradient elution mobile phase consisting of water-acetonitrile for AR13 and AR15 (1:9 v/v, 3:7 v/v) at room temperature $1 \mathrm{ml} / \mathrm{min}$ flow rate, and interfaced with photodiode array detector (PDA) detector, 233 $\mathrm{nm}, 235 \mathrm{~nm}$ respectively.

Results: A linear response was obtained between (range from 0.100-10.00 mg/ml) AR13 and (range from 0.096-9.88 mg/ml) AR15 with correlation coefficient 0.999 and 0.998 . The linearity range of both AR13 and AR15 was $101.65 \pm 1.5$ and $98.78 \pm 1.7$.

Conclusion: It was concluded that the method was simple, accurate, sensitive, accurate and reproducible and has been successfully applied to the pharmacokinetic study of AR13 and AR15 in rat plasma.

Keywords: 1,4-benzothiazine derivatives (AR13 and AR15), Pharmacokinetics, HPLC, Rat plasma

(C) 2017 The Authors. Published by Innovare Academic Sciences Pvt Ltd. This is an open-access article under the CC BY license (http://creativecommons.org/licenses/by/4.0/) DOI: http://dx.doi.org/10.22159/ijpps.2017v9i12.19339

\section{INTRODUCTION}

Analytical methods for appraising drugs and their metabolites in biological samples play an important role in calculating and interpreting data from the studies on bioavailability, bioequivalence, and pharmacokinetics. The 1,4-benzothiazine moiety resemble to phenothiazines, 1,4-benzothiazine was well recognized antipsychotic drugs, [1-2] in 1,4-benzothiazine derivatives having a fold along the nitrogen-sulfur axis can be predictable to possess biological activities like phenothiazine. The 1,4-benothiazine forms significant class of heterocyclic system. The basic unit of the 1,4benzothiazine nucleus present in mammalian red hair and feather [3-4]. The 1,4-benzothiazines are recognized for their usefulness as dyestuffs[5]. The 1,4-benzothiazine are molecules of enormous significance and consider as important targets because of their broad spectrum of biological activities [3]. Literature survey reveals that 1,4-benzothiazines exhibit wide pharmacological activities such as antagonists [6-7], anticancer [8], vasorelaxant [9], antidiabetic [10], antihypertensive [11], antimicrobial [12], analgesic [13], antiHCV [14], antimalarial [15], antithyroid [16] and antitubercular [17]

The 1,4-benzothiazine and thiazole compose an important class of sulfur and nitrogen hetrocytes [18]. Both the active compound AR13 and AR15 are shown in (fig. 1). The structures of these synthesized compounds were drawn in ChemDraw Ultra version 12 (Cambridge Soft) trial version.<smiles>CC1=C(C(=O)NN=Cc2ccccc2Cl)Sc2ccccc2N1</smiles>

(A)<smiles>CC1=C(C(=O)NN=Cc2ccc(Cl)c(Cl)c2)Sc2ccccc2N1</smiles>

(B)

Fig. 1: Structures of analytes (A) AR13 and (B) AR15 both are 1,4-benzothiazine derivatives

\section{MATERIALS AND METHODS}

\section{LC instruments and analytical conditions}

Chromatography separation was performed using the LC-10AD chromatograph (Shimadzu, Japan) with a double pump, vacuum degasser, and 20- $\mu$ l loop manual sample injector, interfaced with PDA detector. (Shimadzu, Japan), all are controlled by the Shimadzu LabSolutions CS software (version 5.3, Alltech, USA). The analytical column was a Shim-pack C18 column ( $250 \mathrm{~mm} \times 4.6 \mathrm{~mm}, 5 \mu \mathrm{m})$.

\section{Reagents and materials}

The compound synthesized at Department of pharmaceutical sciences, Babasaheb Bhimrao Ambedkar University Lucknow, Uttar Pradesh, India. After the In vitro study of the compounds the most active compound as AR13 and AR15 was obtained and further use for pharmacokinetic study. HPLC-grade acetonitrile and water purchased from Himedia Laboratories, Mumbai, India. The following company chemicals were used to synthesize the compound like Sigma-Aldrich, Himedia, and SD Fine. DMH was purchased from M. P. 
Biomedicals U. S. The blood was collected from eppendorf tube. The plasma portion (supernatant) was collected by centrifugation of blood and stored in appropriate aliquots at $-80^{\circ} \mathrm{C}$ ready for use.

\section{Animals and pharmacokinetic studies}

Healthy Albino Wister male rats (120-140 gm) were used for the study. The animal ethical committee already approved this experiment (No. AEC/PHARM/1601/05/2016/R3). The animals were housed under standards norms of the laboratory, the temperature $\left(25 \pm 1{ }^{\circ} \mathrm{C}\right)$ with a light/dark cycle of $12 \mathrm{~h}$ with free access to commercial pellet diet and water. Animals were acclimatized to laboratory conditions for two weeks before the experiment.

The rats were randomly divided into two groups (I and II) for both drugs. AR13 and AR15 (dissolved in $0.25 \%$ carboxymethyl cellulose, CMC) were administered orally at $25 \mathrm{mg} / \mathrm{kg}$ body weight to Albino Wistar rats and blood was collected from retro-orbital $(0.5 \mathrm{ml})$ at 0 , $0.083,0.25,1,2,4,8,24,48$ and $72 \mathrm{~h}$. The blood was collected from retro-orbital plexus $(\mathrm{n}=3)$. A blood sample was collected into ethylenediaminetetraacetic acid (EDTA) containing $2 \mathrm{ml}$ eppendorf tube. After collection, blood was centrifuged at $10,000 \mathrm{rpm}$ for 10 min; plasma was separated and kept at $-80{ }^{\circ} \mathrm{C}$ for further highperformance liquid chromatography determination. The pharmacokinetic parameters of AR13 and AR15 were calculated by WinNonlin software 5.1 software, trial version.

\section{Preparation of working reference and standard solutions}

A stock solution of $1 \mathrm{mg} / \mathrm{ml}$ of both AR13 and AR15 was prepared in acetonitrile. Plasma stock solution of $50 \mu \mathrm{g} / \mathrm{ml}$ was prepared by spiking $10 \mathrm{ml}$ of stock solution in $190 \mathrm{ml}$ of rat plasma. Later, the calibration standard of $0.1,0.2,1,2,5,10$ and $20 \mu \mathrm{g} / \mathrm{ml}(\mathrm{n}=3)$. Quality control (QC) samples $(0.8,2.0$, and $8.0 \mu \mathrm{g} / \mathrm{ml})$ were prepared in a similar manner. Standards and QCs were all then stored at $-80^{\circ} \mathrm{C}$ in appropriate aliquots ready to use.

\section{Sample extraction optimization, preparation of calibrants and test samples}

The extraction efficiency of both compounds was evaluated from rat plasma and evaluated using various solvents i.e. acetonitrile (ACN), ACN: $\mathrm{H}_{2} \mathrm{O}=2: 1$, methanol $\left(\mathrm{CH}_{3} \mathrm{OH}\right)$ and $\mathrm{CH}_{3} \mathrm{OH}: \mathrm{H}_{2} \mathrm{O}=1: 2$. The comparison of liquid-liquid extraction (LLE) was carried out using $100 \mu \mathrm{l} \mathrm{of} 50 \mu \mathrm{g} / \mathrm{ml}$ concentration and $100 \mu \mathrm{l}$ of extracting solvent into a $2 \mathrm{ml}$ eppendorf tube. Then the tubes were vortexed for $30 \mathrm{~min}$ and centrifuged at $10000 \mathrm{rpm}$ for $10 \mathrm{~min}$.

Later, the supernatant was decanted out into another tube and dried in an oven at $40^{\circ} \mathrm{C}$. Later, the tubes were reconstituted with $50 \mu \mathrm{l}$ of various mobile phases, vortexed for $10 \mathrm{~min}$ and $20 \mu \mathrm{l}$ was injected for HPLC-UV analysis. Area under the curve (AUC) data was collected and we found that ACN was the best extracting solvent for both AR13 and AR15 (fig. 2). The fig. were drawn on GraphPad Prism 5 trial version.

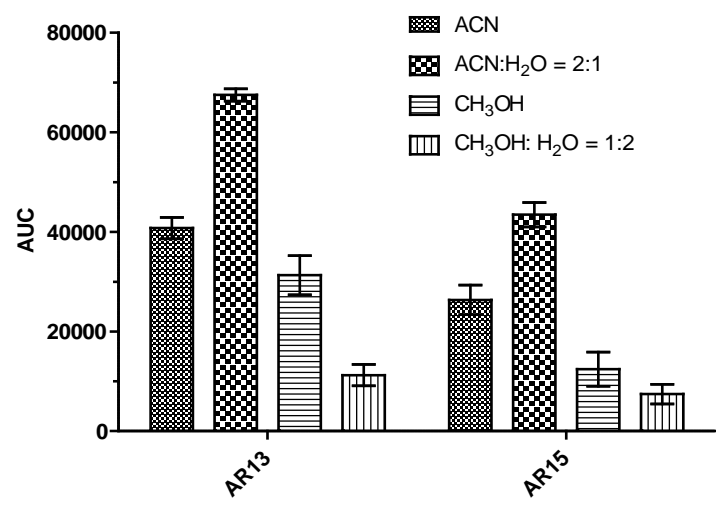

Fig. 2: Showing the solvent effects on AUC of AR13 and AR15 compounds in plasma of rats ACN: Actonitrile; $\mathrm{H}_{2} \mathrm{O}$ : $\mathrm{Water}^{\mathrm{CH}} \mathrm{CH}_{3} \mathrm{OH}$ : $\mathrm{Methanol}$; AR13 and AR15 both are 1,4-benzothiazine derivatives

For the preparation of calibration curve, the above-mentioned calibrants $(100 \mu \mathrm{l})$ were taken into eppendrof tube and $100 \mu \mathrm{l}$ blank ACN was added to it. The remaining procedure was similar to a previously described method. The final concentration of calibration samples were $0.05,0.1,0.2,1,2,5$ and $10 \mu \mathrm{g} / \mathrm{ml}$. The concentrations of QC samples were $0.4,1$ and $4 \mu \mathrm{g} / \mathrm{ml}$.

For test compounds, $100 \mu \mathrm{l}$ of various time point samples were taken into eppendrof tube and $100 \mu \mathrm{l}$ of blank ACN was added to it. Other procedures are same as previous one.

\section{HPLC optimization}

A HPLC (Model-LC-20AD, Shimadzu, Japan) was interfaced with PDA detector. A $20-\mu \mathrm{l}$ plasma sample volume was injected onto a $250 \mathrm{~mm}$ ( $4.6 \mathrm{~mm}$ C18 a Shim-pack column packed with $5 \mu \mathrm{m}$ particles). All analyses were conducted in gradient mode, the mobile phase consisted of water-acetonitrile for AR13 and AR15 (1:9v/v, 3:7 v/v) with a flow rate of $1.0 \mathrm{ml} / \mathrm{min}$ and ambient temperature. Interfaced with PDA detection was at 233 and $235 \mathrm{~nm}$.

Total run time was 6 and 7 min. respectively. Peak reorganization was based on identical the sample peak retention time with that of previously run AR13 and AR15 standards under matching conditions. The column was washed after every run in an elution solvent ratio (50:50) with the injection of blank ACN.

\section{Stability studies}

Long-term stability of AR13 and AR15 were performed by preparing QC samples at three concentration ranges in three replicates like $(0.1,2$ and $10 \mu \mathrm{g} / \mathrm{ml})$ low, medium and high concentrations respectively for four dissimilar days and stored at $4{ }^{\circ} \mathrm{C}$.

The analysis of all these samples was performed after $0,7,15$ and 30 $\mathrm{d}$ of storage and the data of samples were calculated by the particular calibration standard curve. The results revealed as \% deviation from $0 \mathrm{~d}$ concentration.

Moreover, the short-term stability was also carried out at room temperature over $8 \mathrm{~h}$ by analyzing replicates $(n=3)$ at three QC levels.

\section{Method development and validation}

The inter-day and intra-day accuracy was confirmed by calculating $\%$ bias from the theoretical concentration via equation (\% bias = (observed Conc.-nominal Conc.)/nominal Conc. × 100) of quality control samples [19]. The inter-day and intra-day precisions were 
calculated by subjecting the data to the one-way analysis of variance (ANOVA) with regards to relative standard deviation (\% RSD). Evaluations of pharmacokinetic parameters of both compounds were performed by using WinNonlin 5.1 software, trial version.

\section{RESULTS}

All plasma samples were analyzed successfully using HPLC. All steps were analyzed to get good selectivity, sensitivity, and reproducibility of AR13 and AR15 in rat plasma.

\section{Optimization of plasma sample pretreatment conditions}

LLE extraction followed by HPLC analysis demonstrated that both AR13 and AR15 are the non-polar compounds. In the meantime, we played with an eluting solvent with various ratios $\left(\mathrm{ACN}: \mathrm{H}_{2} \mathrm{O}\right.$, 90:10, 70:30, 50:50, 30:70 and 10:90) to separate out AR13 in HPLC column. As per result obtained, we found that 90:10 had the highest area under the curve (AUC) with a retention time (RT) 3.30 min (fig. 3). Another experiment was carried out with AR15 for separation of above-mentioned solvent ratio with the adjustment of 70:30 ratio.

Finally, we decided to elute AR15 with 70:30 ratio with RT 3.77 min (fig. 3) as this ratio of solvent gave better AUC than any other solvent ratios.

Later, this optimized method was adopted to run the calibrants, QC and tested samples. Finally, data were calculated through WinNonlin 5.1 trial version.
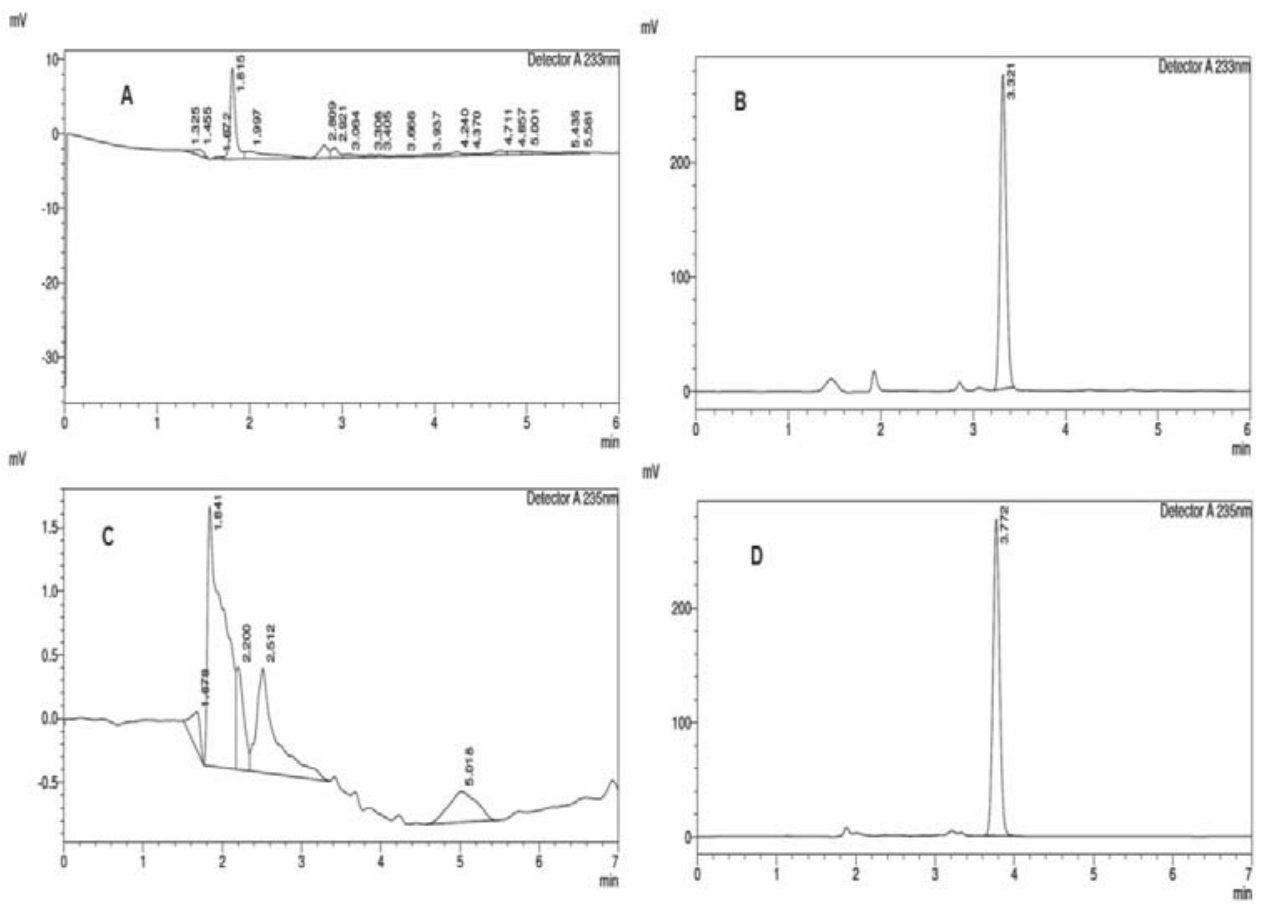

Fig. 3: Typical chromatograms are showing the $\mathrm{RT}$ as following (A) blank rat's plasma, (B) rat plasma spiked with AR13 at $233 \mathrm{~nm}$ and (C) blank rats' plasma, (D) rat plasma spiked with AR15 at $235 \mathrm{~nm}$

\section{Method validation}

The validated method was again used to summarize specificity, linearity, lower limit of quantitation (LLOQ), accuracy and precession. Specificity had already been discussed in the previous section. Best linearity was found to be the ranges from 0.1 to $10 \mu \mathrm{g} / \mathrm{ml}$ with $\mathrm{r}^{2}$ of 0.999 and 0.998 for AR13 and AR15 respectively. However, LLOQ was $0.01 \mu \mathrm{g} / \mathrm{ml}$ which revealed that our optimized method might be useful for any derivatives of 1,4-benzothiazine in future. Inter-day and intra-day precision were measured in this experiment using means and \% relative standard deviation (RSD) at six different concentrations of three replicates for AR13 and AR15, results are shown in (table 1).

The \%RSD values were within the limit of $\pm 20 \%$ for both compounds which signified that our methods are precious in every aspect.

Table 1: The intra-day and inter-day precision of AR13 and AR15 in rat plasma

\begin{tabular}{|c|c|c|c|c|c|}
\hline \multirow[t]{2}{*}{ Compounds } & \multirow{2}{*}{$\begin{array}{l}\text { Spiked concentration } \\
(\mu \mathrm{g} / \mathrm{ml})\end{array}$} & \multicolumn{2}{|l|}{ Intra-day precision } & \multicolumn{2}{|l|}{ Inter-day precision } \\
\hline & & mean $\pm S D(\mu \mathrm{g} / \mathrm{ml})$ & RSD (\%) & mean $\pm S D(\mu \mathrm{g} / \mathrm{ml})$ & RSD (\%) \\
\hline \multirow[t]{6}{*}{ AR13 } & 0.1 & $0.09 \pm 0.005$ & 2.43 & $0.07 \pm 0.006$ & 3.21 \\
\hline & 0.5 & $0.54 \pm 0.02$ & 5.74 & $0.47 \pm 0.05$ & 5.74 \\
\hline & 1.0 & $1.21 \pm 0.08$ & 7.32 & $0.98 \pm 0.21$ & 7.21 \\
\hline & 2.0 & $1.98 \pm 0.32$ & 2.54 & $1.84 \pm 0.31$ & 4.87 \\
\hline & 5.0 & $5.06 \pm 0.54$ & 1.98 & $4.94 \pm 0.17$ & 6.41 \\
\hline & 10.0 & $10.02 \pm 0.12$ & 6.87 & $9.91 \pm 0.42$ & 2.34 \\
\hline \multirow[t]{6}{*}{ AR15 } & 0.1 & $0.1 \pm 0.002$ & 1.48 & $0.9 \pm 0.005$ & 1.52 \\
\hline & 0.5 & $0.54 \pm 0.07$ & 7.51 & $0.48 \pm 0.02$ & 3.45 \\
\hline & 1.0 & $1.08 \pm 0.04$ & 5.32 & $0.98 \pm 0.04$ & 6.98 \\
\hline & 2.0 & $2.09 \pm 0.34$ & 8.95 & $1.95 \pm 0.72$ & 3.21 \\
\hline & 5.0 & $5.02 \pm 0.24$ & 4.87 & $4.87 \pm 0.23$ & 5.32 \\
\hline & 10.0 & $10.05 \pm 0.31$ & 2.89 & $9.89 \pm 0.61$ & 7.98 \\
\hline
\end{tabular}

Mean: average of number of experiment; SD: standard deviation; RSD: relative standard deviation (mean $\pm \mathrm{SD}, \mathrm{n}=3$ ) 
The \% accuracy and \% RSD were determined by analyzing the percentage recovery of AR13 and AR15 in plasma samples. The analyses of compounds were performed at three concentrations $(0.1,0.5$ and $1 \mu \mathrm{g} / \mathrm{ml})$ in three replicates for AR13 and AR15, receptively. The average recovery of AR13 and AR15 were $101.6 \%$ and $98.8 \%$ with RSD of $1.6 \%$ and $1.7 \%$ respectively, which showed the accuracy of the method.

Stability study was another important parameter to be considered for every pharmacokinetic study. AR13 and AR15 were found to be stable over a period of $30 \mathrm{~d}$ in normal plasma when stored at $4{ }^{\circ} \mathrm{C}$. The short-term stability was carried out at room temperature over $8.0 \mathrm{~h}$, and long-term also performed after $30 \mathrm{~d}$ preservation by using three replicates at three concentration levels.

The percent deviation was calculated and found within acceptable range $\pm 20 \%$ at low concentration and within $\pm 15 \%$ for all other remaining concentrations. The calculated stability of spiked plasma is shown in table 2, which indicated that AR13 and AR15 had no considerable degradation under the environment described earlier.

Table 2: Shows the short-term and long-term stability of AR13 and AR15 in rat plasma

\begin{tabular}{|c|c|c|c|c|c|}
\hline \multirow[t]{2}{*}{ Compounds } & \multirow{2}{*}{$\begin{array}{l}\text { Spiked concentration } \\
(\mu \mathrm{g} / \mathrm{ml})\end{array}$} & \multicolumn{2}{|l|}{ Short-term stability } & \multicolumn{2}{|l|}{ Long-term stability } \\
\hline & & mean $\pm S D(\mu g / m l)$ & RSD (\%) & mean $\pm S D(\mu \mathrm{g} / \mathrm{ml})$ & RSD (\%) \\
\hline \multirow[t]{3}{*}{ AR13 } & 0.10 & $0.12 \pm 0.002$ & 1.7 & $0.10 \pm 0.015$ & 1.9 \\
\hline & 2.00 & $2.03 \pm 0.08$ & 1.3 & $1.99 \pm 0.08$ & 1.7 \\
\hline & 10.0 & $9.96 \pm 2.8$ & 2.1 & $10.04 \pm 2.12$ & 2.1 \\
\hline \multirow[t]{3}{*}{ AR15 } & 0.10 & $0.14 \pm 0.491$ & 2.1 & $0.11 \pm 0.871$ & 1.4 \\
\hline & 2.00 & $2.21 \pm 3.41$ & 1.6 & $2.06 \pm 1.32$ & 0.7 \\
\hline & 10.0 & $10.24 \pm 2.93$ & 0.9 & $10.09 \pm 4.29$ & 1.7 \\
\hline
\end{tabular}

Mean: average of number of experiment; SD: standard deviation; RSD: relative standard deviation (mean \pm SD, $n=3$ )

\section{Pharmacokinetic study}

The newly developed and validated method was utilized in the pharmacokinetic study of AR13 and AR15 after orally

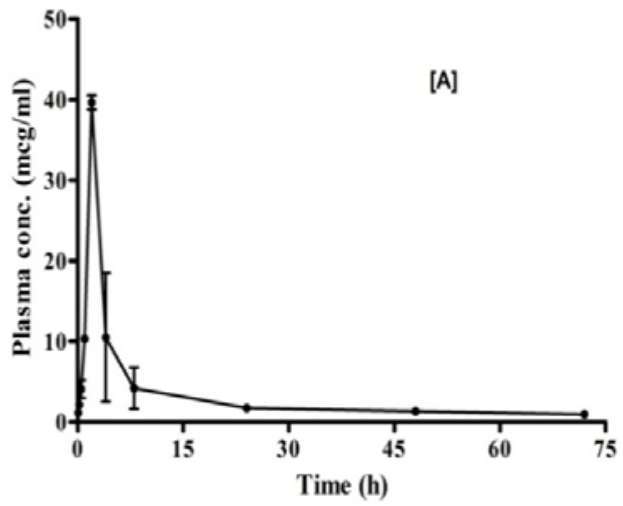

administered $25 \mathrm{mg} / \mathrm{kg}$ dose. The mean plasma concentrationtime profile of AR13 and AR15 compound in male rate are shown in (fig.4). The fig. was drawn on GraphPad Prism 5 trial version.

Fig. 4: Plasma drug concentrations after single oral administration of AR13 [A] and AR15 [B] at $25 \mathrm{mg} / \mathrm{kg}$ dose

The calculated non-compartment model parameters of pharmacokinetic study are summarized in table 3 where the $C_{\max }$, $\mathrm{T}_{\max }$, and $\mathrm{AUC}_{0-\infty}$ were found to be $39.65 \pm 0.88 \mu \mathrm{g} / \mathrm{ml}, 2.0 \mathrm{~h}$, $221.06 \pm 56.218 \mu \mathrm{g} . \mathrm{h} / \mathrm{ml}$ for AR13 and $19.79 \pm 3.39 \mu \mathrm{g} / \mathrm{ml}, 2.0 \mathrm{~h}$, $117.99 \pm 14.21 \mu \mathrm{g} . \mathrm{h} / \mathrm{ml}$ for AR15, respectively. The data represented in fig. 4 clearly explained that both compounds had slow absorption rate which is useful for colon cancer treatment as they remain in the

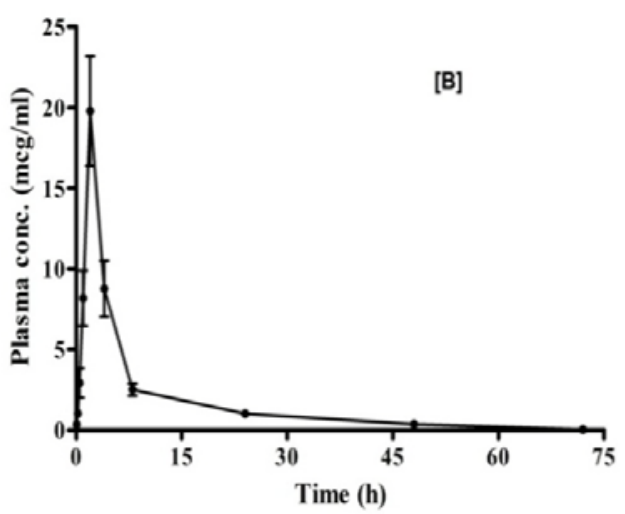

gastrointestinal tract (GIT) for the higher amount with the promising effect of AR13. The mean residential time (MRT) was found as $17.33 \pm 1.75 \mathrm{~h}$ and $11.11 \pm 2.19 \mathrm{~h}$ of the AR13 and AR15 respectively. Both had a higher volume of distribution in plasma which could be easily seen form their MRT results. AR13 had higher clearance rate (CL) than AR15 (table 3) again explained the better effectiveness of AR13.

Table 3: Various pharmacokinetic parameters after single oral administration of 25 mg/kg of AR13 and AR15

\begin{tabular}{lll}
\hline Parameters & AR13 & AR15 \\
\hline $\mathrm{C}_{\max }(\mu \mathrm{g} / \mathrm{ml})$ & $39.65 \pm 0.88$ & $19.79 \pm 3.39$ \\
$\mathrm{~T}_{\max }(\mathrm{h})$ & 2.00 & 2.00 \\
$\mathrm{AUC}_{0-\infty}(\mu \mathrm{g} . \mathrm{h} / \mathrm{ml})$ & $221.06 \pm 56.21$ & $117.99 \pm 14.21$ \\
$\mathrm{AUMC}\left(\mu \mathrm{g} . \mathrm{h}^{2} / \mathrm{ml}\right)$ & 3784.38 & 1306.14 \\
$\mathrm{MRT}(\mathrm{h})$ & $17.332 \pm 1.75$ & $11.11 \pm 2.19$ \\
$\mathrm{CL}(\mathrm{mL} / \mathrm{h})$ & 0.004 & 0.01 \\
\hline
\end{tabular}

$\mathrm{C}_{\max }$ : maximum drug concentration in plasma; $\mathrm{T}_{\max }$ : time at which the $\mathrm{C}_{\max }$ observed; $\mathrm{AUC}$ : area under curve; $\mathrm{AUMC}$ : area under the first movement curve; MRT: mean residual time; CL: clearance rate (mean $\pm \mathrm{SD}, n=3$ ) 


\section{DISCUSSION}

The current study develops and validates HPLC method using a liquidliquid extraction (LLE) method for the quantification of AR13 and AR15 as potent new antipsychotic drugs $[1,2]$ in rat plasma. LLE is a wellestablished technique for the extraction of concentrated, high-purity samples from a broad range of biological samples. An appropriate LLE solvent is used to eliminate the sample medium and take out the analyte since matrix effect occurs due to the presence of other ions in the biological sample. A number of common organic solvents such as dichloromethane, chloroform, acetonitrile and methanol were used to extract AR13 and AR15 from spiked blood plasma. On contrast to other organic solvents, acetonitrile was most efficient solvent for the recovery of both compounds and reduced milieu effects. Therefore, LLE with acetonitrile was used for the sample preparation of AR13 and AR15 in this study. The signal intensities for AR13 and AR15 steadily increased on increasing the percentage of acetonitrile from 10 to $90 \%$ and slowly decreased from $90 \%$. Thus, the mobile phase composed of aqueousacetonitrile $(10: 90$, and 30:70 v/v respectively) was chosen for the present method. Sample separation on a Shim-pack C18 column (250 $\mathrm{mm} \times 4.6 \mathrm{~mm}, 5 \mu \mathrm{m}$, Shimadzu version 5.3, Alltech, USA) was done. Column resulted in symmetrical peaks for both the compounds i.e. AR13 and AR15 with a relatively short retention time (RT) $3.30 \mathrm{~min}$ and 3.77 $\mathrm{min}$, respectively. The symmetrical peaks and adequate separation were confirmed from the results of fig. 3. Therefore, these analytical conditions were used in succeeding studies. The precision and the accuracy of the method were confirmed. As shown in table 1, the intraday and inter-day precision of the method was lower than $10 \%$, indicating acceptable values for an assay validation [20]. In addition, the short-term and long-term stability of AR13 and AR15 in rat plasma was evaluated as shown in table 2, which indicated that AR13 and AR15 were stable during in this study. Therefore, these conditions were not affecting the quantification of AR13 and AR15 in rat plasma.

\section{CONCLUSION}

Single oral dose non-compartment studies on newly synthesized pharmacologically active compounds are the primary criteria for performing pharmacodynamics studies. Synthesized AR13 and AR15 are effective against in vitro HT-29 cell lines and hence we performed in vivo pharmacokinetic studies in single oral dose. Results come out from our experiment clearly explained both compounds had a lower rate of absorption, higher volume of distribution and lower clear rate which is particularly indicated a good pharmacological response. The researcher had already adopted various HPLC-UV methods to find out the pharmacokinetic parameters of 1,4-benzothiazine derivatives previously. However, our optimized methods are more potent to a researcher with respect to accuracy and precision as compared to previously publish data where few derivatives of 1,4-benzothiazine had been optimized for pharmacokinetic studies using HPLC-UV method. Future aspect of the project is to perform in vivo testing of chemically induced colon carcinogenic rat model of these compounds.

\section{ACKNOWLEDGMENT}

The authors wish to express their thanks to Department of Pharmaceutical Sciences, Babasaheb Bhimrao Ambedkar University, Lucknow, India for providing the HPLC and research facilities.

\section{AUTHORS CONTRIBUTION}

Design and experiment part of the work was done by Mr. Amit Rai and Mr. Amit K. Keshari. Writing of the work was done by Mr. Vinit Raj and Mr. Ashok K. Singh and The design of the work and correction of the manuscript was done by the corresponding author Dr. Sudipta Saha.

\section{CONFLICT OF INTERESTS}

The authors confirm that this article content has no conflict of interest

\section{REFERENCES}

1. Spiegelberg U, Kleu G. Psychiatric-neurologic experiences a new psychopharmacological drug. Arzneim Forsch 1967;17: 159-72.
2. Barker JC, Miller M. A double-blind comparative trial of pericyazine and thioridazine in chronic schizophrenia. $\mathrm{Br} J$ Psychiatry 1969;115:169-72.

3. Gupta RR. Phenothiazines and 1,4-benzothiazines chemical and biomedical aspects. Elsevier, Amsterdam; 1988.

4. Pasadena CA, Keyzer ed H, Eskert GM, Forrest IS, Gupta RR, Gutmamn F, et al. Thiazines and structurally related compounds, proceedings of the sixth international conference of phenothiazines and structurally psychotropic compounds. Kriger Publishing Co., Malbar, FL, USA; 1992.

5. Tanaka R, Teramura K, Yokoyama S. Japanese Patent 41/5833 (1966) [Chem Abstr 65, 9062; 1966.

6. Watanabe Y, Osanai K, Nishi T, Miyawaki N, Shii D, Honda T, et al. Synthesis of azido derivatives of semotiadil, a novel 1, 4benzothiazine calcium antagonist, for photoaffinity probes of calcium channels. Bioorg Med Chem Lett 1996;6:1923-26Y.

7. Schwarzl I, Stark U, Brodmann M, Haiden U, Tritthart HA, Stark G. Efficacy of the novel calcium antagonist R (+)-semotiadil in limiting the ventricular rate during atrial flutter in isolated guinea pig hearts. J Cardiovasc Pharmacol 2000;35:309-14.

8. Niewiadomy A, Matysiak J, Karpinska MM. Synthesis and anticancer activity of new 2-Aryl-4H-3, 1-benzothiazines. Arch Pharm 2011;344:224-30.

9. Martelli A, Manfroni G, Sabbatini P, Barreca ML, Testai L, Novelli M, et al. 1, 4-Benzothiazine ATP-sensitive potassium channel openers: modifications at the $\mathrm{C}-2$ and $\mathrm{C}-6$ positions. J Med Chem 2013;56:4718-28.

10. Meltzer-Mats E, Babai-Shani G, Pasternak L, Uritsky N, Getter T, Viskind 0 , et al. Synthesis and mechanism of hypoglycemic activity of benzothiazole derivatives. J Med Chem 2013;56:5335-50.

11. Cecchetti V, Schiaffella F, Tabarrini 0, Fravolini A. (1,4Benzothiazinyloxy) alkylpiperazine derivatives as potential antihypertensive agents. Bioorg Med Chem Lett 2000;10:465-8.

12. Brincat JP, Carosati E, Sabatini S, Manfroni G, Fravolini A, Raygada JL, et al. Discovery of novel inhibitors of the Nor A multidrug transporter of Staphylococcus aureus. J Med Chem 2010;54:354-65.

13. Warren BK, Knaus EE. Pyridine and reduced pyridine analogues of 10H-pyrido [3,4-b][1,4] benzothiazines with analgesic activity. Eur J Med Chem 1987;22:411-15.

14. Hendricks RT, Fell JB, Blake JF, Fischer JP, Robinson JE, Spencer $\mathrm{SR}$, et al. Non-nucleoside inhibitors of HCV NS5B polymerase. Part 1:Synthetic and computational exploration of the binding modes of benzothiadiazine and 1, 4-benzothiazine HCV NS5b polymerase inhibitors. Bioorg Med Chem Lett 2009;19:3637-41.

15. Barazarte A, Lobo G, Gamboa N, Rodrigues JR, Capparelli MV, Alvarez-Larena A, et al. Synthesis and antimalarial activity of pyrazolo and pyrimido benzothiazine dioxide derivatives. Eur J Med Chem 2009;44:1303-10.

16. Hasegawa $K$, Ito $S$, Inoue $S$, Wakamatsu $K$, Ozeki H, Ishiguro I. Dihydro-1,4-benzothiazine-6,7-dione, the ultimate toxic metabolite of 4-S-cysteaminylphenol and 4-Scysteaminylcatechol. Biochem Pharmacol 1997;53:1435-44.

17. Coughlin SA, Danz DW, Robinson RG, Klingbeil KM, Wentland $\mathrm{MP}$, Corbett TH, et al. Mechanism of action and antitumor activity of (S)-10-(2,6-dimethyl-4-pyridinyl)-9-fluoro-3methyl-7-oxo-2,3-dihydro-7H-pyridol[1,2,3-de]$[1,4]$ benzothiazine-6-carboxylicacid (WIN58161). Biochem Pharmacol 1995;50:111-22.

18. Rai A, Raj V, Singh AK, Keshari AK, Kumar U, Kumar D, et al. Design and synthesis of 1, 4-benzothiazine derivatives with promising effects against colorectal cancer cells. Cog Chem 2017;3:1303-909.

19. Shah S, Dhanani T, Kumar S. Validated HPLC method for identification and quantification of p-hydroxy benzoic acid and agnuside in Vitex negundo and Vitex trifolia. J Pharm Anal 2013;3:500-8.

20. Rockville MD. Food and Drug Administration. Guidance for industry: Bioanalytical method validation. Center Drug Evaluation Res 2001. p. 1-14. 